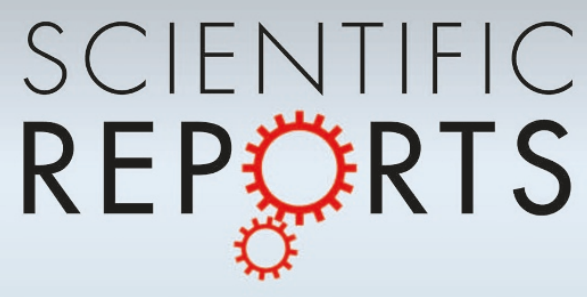

OPEN

SUBJECT AREAS:

NANOPARTICLES

MAGNETIC PROPERTIES AND MATERIALS

Received

28 November 2014

Accepted

23 January 2015

Published

4 March 2015

Correspondence and requests for materials should be addressed to

X.L. (liuxh@csu.edu.cn) or G.Q. (qgz@csu. edu.cn)

\section{Controllable fabrication and magnetic properties of double-shell cobalt oxides hollow particles}

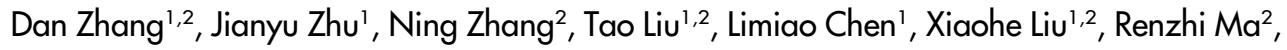 \\ Haitao Zhang ${ }^{3} \&$ Guanzhou Qiu'
}

\begin{abstract}
${ }^{1}$ School of Resources Processing and Bioengineering, Central South University, Changsha, Hunan 410083, PR China, ${ }^{2}$ School of Materials Science and Engineering, Central South University, Changsha, Hunan 410083, PR China, ${ }^{3}$ Institute of Process Engineering, Chinese Academy of Sciences, Beijing 100190, P. R. China.
\end{abstract}

Double-shell cobalt monoxide ( $\mathrm{CoO})$ hollow particles were successfully synthesized by a facile and effective one-pot solution-based synthetic route. The inner architecture and outer structure of the double-shell CoO hollow particles could be readily created through controlling experimental parameters. A possible formation mechanism was proposed based on the experimental results. The current synthetic strategy has good prospects for the future production of other transition-metal oxides particles with hollow interior. Furthermore, double-shell cobalt oxide $\left(\mathrm{Co}_{3} \mathrm{O}_{4}\right)$ hollow particles could also be obtained through calcinating corresponding $\mathrm{CoO}$ hollow particles. The magnetic measurements revealed double-shell $\mathrm{CoO}$ and $\mathrm{Co}_{3} \mathrm{O}_{4}$ hollow particles exhibit ferromagnetic and antiferromagnetic behaviour, respectively.

M ultiple-shell hollow particles have attracted widely attention in recent years because of the promising properties and potential applications in various fields, such as lithium-ion batteries ${ }^{1-4}$, sensors ${ }^{5,6}$, photocatalysis $^{7,8}$, dye-sensitized solar cells (DSSCs) ${ }^{9,10}$, drug/gene delivery ${ }^{11}$, microreactors ${ }^{12}$, and so forth. A variety of methods including template-assisted synthesis ${ }^{13}$, ionic exchange reaction ${ }^{14}$, Ostwald ripening ${ }^{15-18}$, Kirkendall effects ${ }^{19}$, and selective etching process ${ }^{20,21}$ have been developed to fabricate multiple-shell hollow particles. Among these methods, Ostwald ripening, a well-known physical phenomenon, which contains that the smaller size particles dissolving into the liquid phase as a nutrient supply for the growth of larger crystals and results in the formation of the hollow interior spaces, is one of the most effective approaches to the rational design of complex hollow structures. Up to now, remarkable progress has been made for the fabrication of multiple-shell hollow structures by Ostwald ripening process. In particular, wang and co-workers demonstrated a multistep Ostwald ripening approach for the geometry-controlled fabrication of $\mathrm{Cu}_{2} \mathrm{O}$ particles with multilayered shell-inshell interior structures ${ }^{22}$. Zeng and co-workers reported the synthesis of double-shell $\mathrm{SiO}_{2}$ hollow spheres via Ostwald ripening process under solvothermal condition ${ }^{23}$. Very recently, a family of multiple-shell structures, $\left(\mathrm{Cu}_{2} \mathrm{O} @\right) \mathrm{nCu}_{2} \mathrm{O}(\mathrm{n}=1-4)$, has been synthesized through Ostwald ripening treatment at room temperature ${ }^{24}$. Despite these successes, developing the Ostwald ripening methods for the fabrication of multiple-shell hollow particles remains a highly sophisticated challenge.

Cobalt oxides have drawn increasing attention in the past decades on the basis of their distinctive electronic, magnetic, and catalytic properties and wide variety of applications. It is well known that $\mathrm{CoO}$ and $\mathrm{Co}_{3} \mathrm{O}_{4}$ are two especially important forms among the various cobalt oxides based on their distinctive structural features and fascinating properties. Generally, $\mathrm{CoO}$, crystallizing in the rocksalt $(\mathrm{NaCl})$-like structure, consists of two facecentered-cubic (fcc) sublattices of $\mathrm{Co}^{2+}$ and $\mathrm{O}^{2-}$ ions, while $\mathrm{Co}_{3} \mathrm{O}_{4}$ belongs to the spinel-like structure based on a cubic close packing array of oxide ions, in which $\mathrm{Co}^{2+}$ ions occupy the tetrahedral 8 a sites and $\mathrm{Co}^{3+}$ ions occupy the octahedral $16 \mathrm{~d}$ sites ${ }^{25}$. Because of the unique morphology-dependent properties, immense efforts have been dedicated to developing facile and effective approaches for the preparation of cobalt oxides with controllable morphologies, such as nanocon $e^{26,27}$, nanobelt ${ }^{28}$, nanoring ${ }^{29}$, nanocube $e^{30-33}$, nanowire ${ }^{34}$, nanotube ${ }^{35}$, hollow sphere $^{36}$, etc. Recently, wang and co-workers have achieved a significant breakthrough in the synthesis of multiple-shell cobalt oxides hollow spheres by the use of carbonaceous microspheres (CMSs) as sacrificial templates ${ }^{37,38}$. Unfortunately, template-assisted synthesis generally involves tedious procedures including preparation of sacrificial templates, deposition of the designed materials, and selective removal of the templates via 

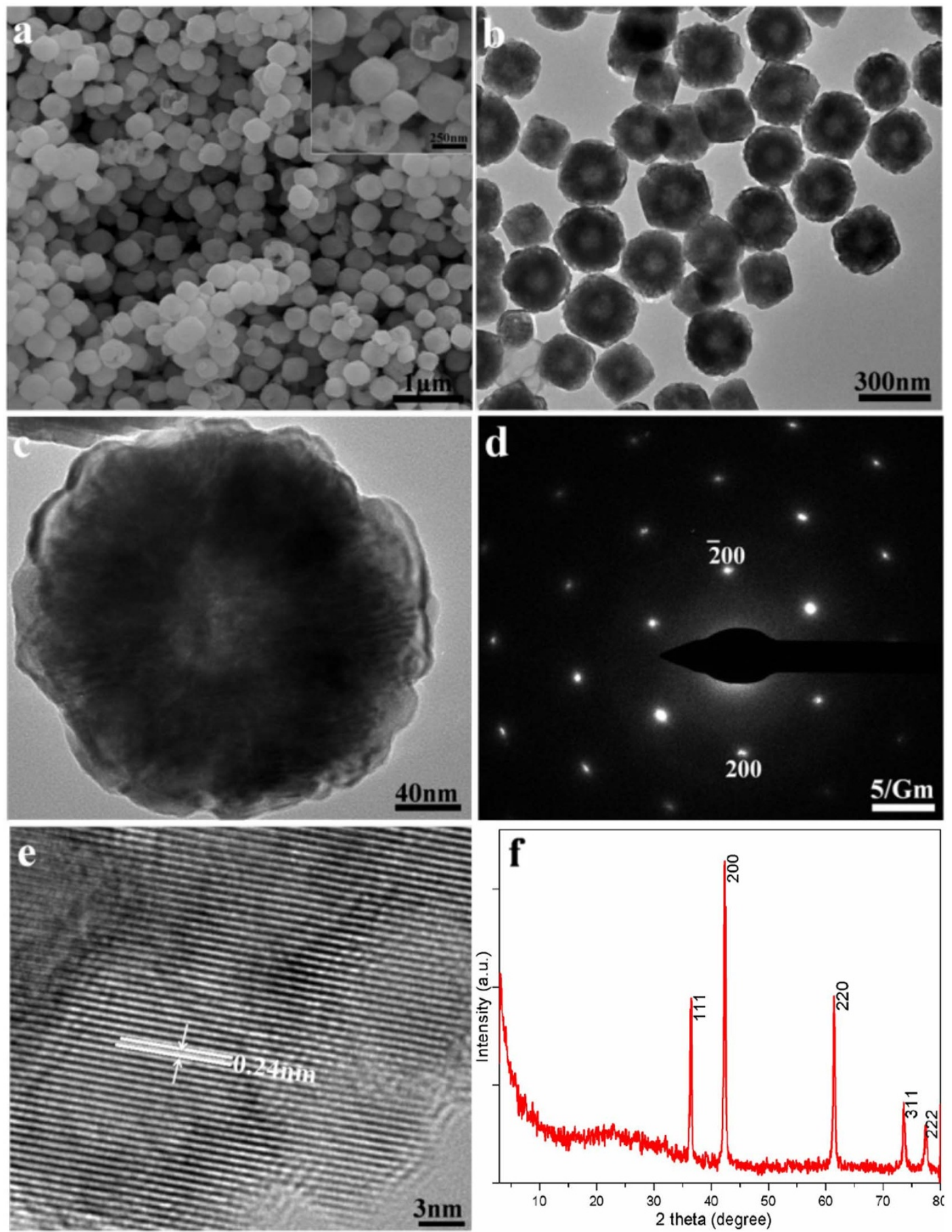

Figure 1 Solvothermal synthesis of double-shell CoO hollow particles obtained at $260^{\circ} \mathrm{C}$ for $8 \mathrm{~h}$. (a) SEM and (b, c) TEM images. The inset in a) shows a higher magnification SEM image. (d) SAED pattern and (e) HRTEM image of the individual double-shell CoO hollow particle. (f) XRD pattern of as-prepared double-shell $\mathrm{CoO}$ hollow particles obtained at $260^{\circ} \mathrm{C}$ for $8 \mathrm{~h}$.

chemical etching or thermal decomposition. On the other hand, the removal of the CMSs templates may result in very low yield of target product based on the ion-absorption, which is unfavorable to fulfilling the application prospects of the multiple-shell hollow spheres.

Herein, we present a one-pot solvothermal method to prepare double-shell CoO hollow particles. Interestingly, the inner and outer architecture of the double-shell CoO hollow particles can be readily tuned through controlling experimental parameters. The results demonstrate that the double-shell hollow particles might form through Ostwald ripening. By using $\mathrm{CoO}$ hollow particles as the precursor, double-shell $\mathrm{Co}_{3} \mathrm{O}_{4}$ hollow particles can also be obtained via thermal decomposition process. Notably, the current synthetic strategy may provide an effective route for the synthesis of other transition-metal oxides particles, and is thus promising for achieving unique architectures with hollow interior for a wide range of applications.

\section{Results}

Figure 1a displays a representative SEM image of as-prepared product obtained using cabalt (II) acetylacetonate as cobalt source at $260^{\circ} \mathrm{C}$ for $8 \mathrm{~h}$, in which a large quantity of near-spherical particles with good uniformity were achieved under current conditions. The 


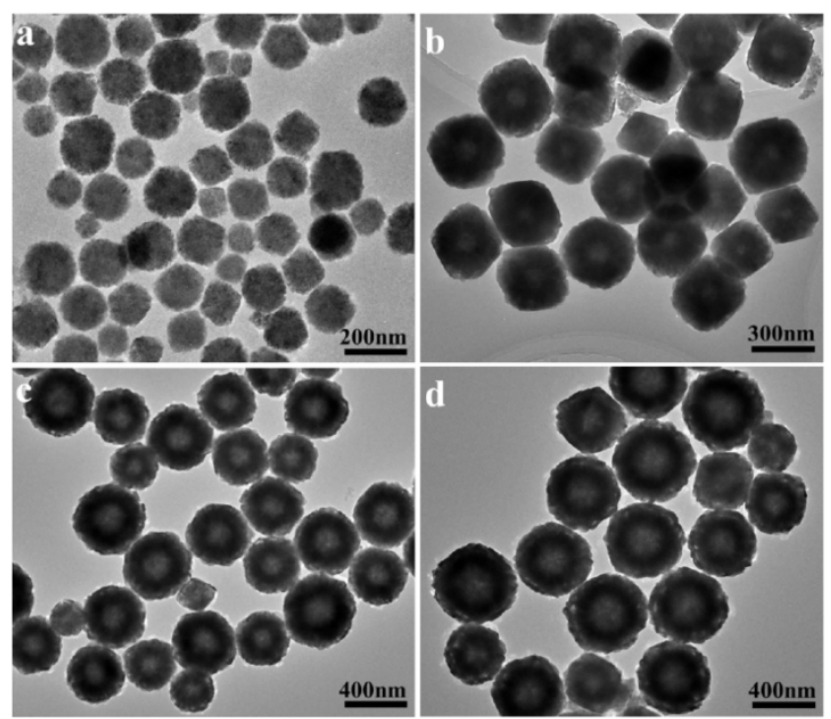

Figure $2 \mid$ TEM images of $\mathrm{CoO}$ particles prepared at $260^{\circ} \mathrm{C}$ for varied time durations: (a) $1 \mathrm{~h}$, (b) $4 \mathrm{~h}$, (c) $12 \mathrm{~h}$, and (d) $24 \mathrm{~h}$.

particles have a mean size of about $300 \mathrm{~nm}$. There exist many broken particles, which reveals that $\mathrm{CoO}$ particles obviously possess hollow interiors. The inset is a high-magnification SEM image obtained from a selected area of Figure 1a. Herein, the hollow interiors of as-prepared $\mathrm{CoO}$ particles can be clearly identified. Figure $1 \mathrm{~b}$ presents a typical TEM image of $\mathrm{CoO}$ particles, which also evidently exhibits $\mathrm{CoO}$ particles with hollow interiors. Figure 1c indicates a typical TEM image of an individual CoO hollow particle. With careful observation, the double-shell structure of CoO hollow particle can be clearly observed. The outer and inner shell thicknesses of the double-shell CoO hollow particle are estimated to be about 8 and $100 \mathrm{~nm}$, respectively. A selected area electron diffraction (SAED) pattern taken from the individual CoO hollow particles, as shown in Figure 1d, illustrates single-crystalline structure of double-shell $\mathrm{CoO}$ hollow particles. Figure 1e depicts the HRTEM image of the individual particle. The lattice spacing is calculated to be about $0.24 \mathrm{~nm}$, agreeing well with the value of $\{111\}$ lattice planes of cubic $\mathrm{CoO}$. The crystal structures of as-prepared products were characterized by X-ray powder diffraction (XRD). All of the reflections of the XRD pattern, as shown in Figure 1f, can be readily indexed as a facecentered cubic phase of CoO (JCPDS 65-2902) with lattice constant $a=0.426 \mathrm{~nm}$ (space group: Fm-3m (No. 225)). No impurity peak was observed, indicating the high purity of the product obtained under such conditions. The sharp diffraction peaks also reflects the good crystallinity of as-prepared product.

For a better understanding of the growth process of double-shell hollow particles, the influences of reaction time on the morphologies of products have been investigated. Figure 2 summarizes a series of morphological observations supposed to be in different stages of forming double-shell hollow particles. When the reaction time was decreased to $1 \mathrm{~h}$, the product is mostly made up of near-spherical
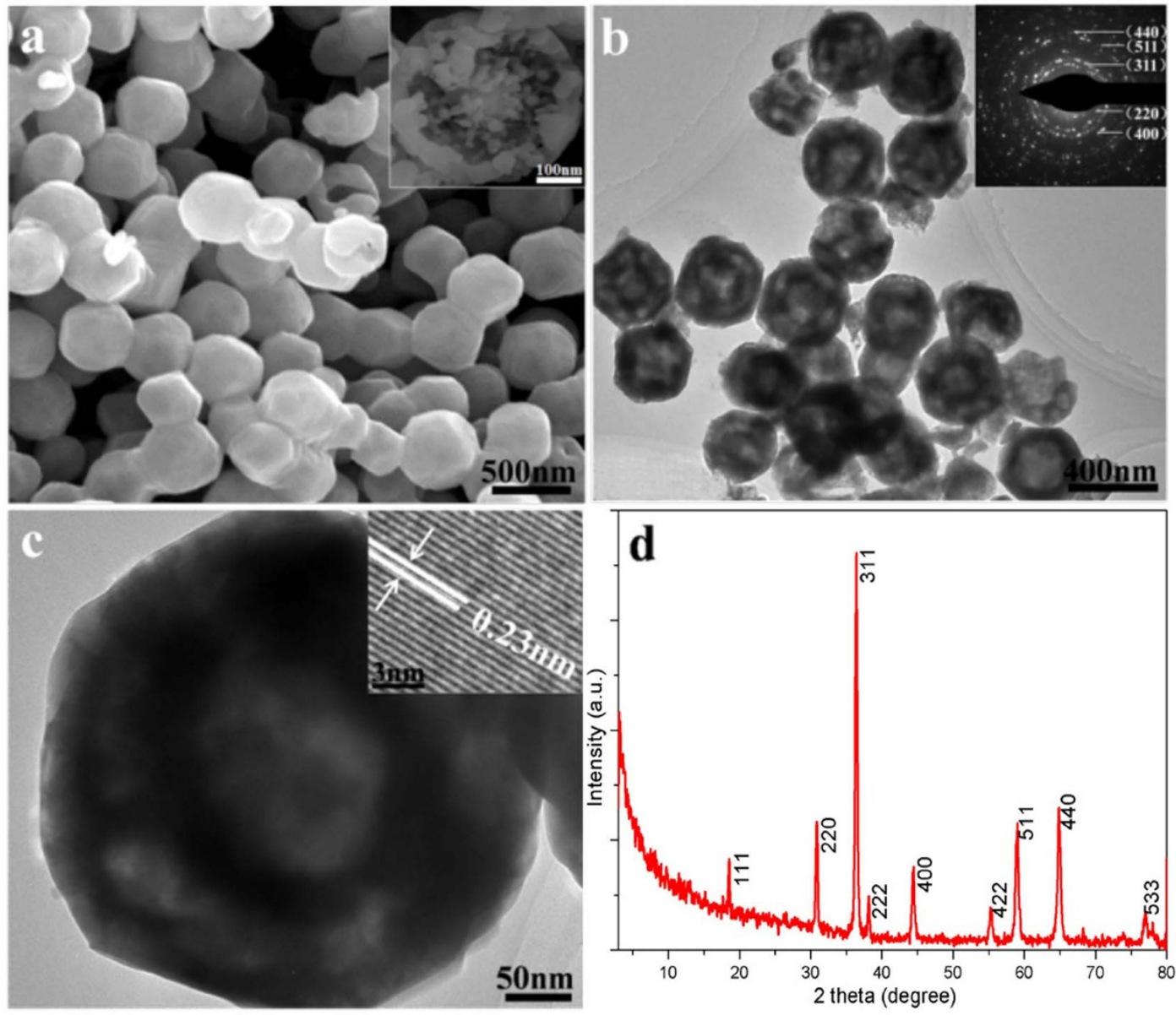

Figure 3 (a) SEM image of double-shell $\mathrm{Co}_{3} \mathrm{O}_{4}$ hollow particles obtained by calcination of as-prepared CoO hollow particles at $600^{\circ} \mathrm{C}$ for $2 \mathrm{~h}$ in air. The inset shows an individual $\mathrm{Co}_{3} \mathrm{O}_{4}$ hollow particle. (b) Low- and (c) high-magnification TEM images of double-shell $\mathrm{Co}_{3} \mathrm{O}_{4}$ hollow particles.

The insets in (b) and (c) show SAED pattern and HRTEM image of double-shell $\mathrm{Co}_{3} \mathrm{O}_{4}$ hollow particles, respectively. (d) XRD pattern of as-prepared double-shell $\mathrm{Co}_{3} \mathrm{O}_{4}$ hollow particles. 

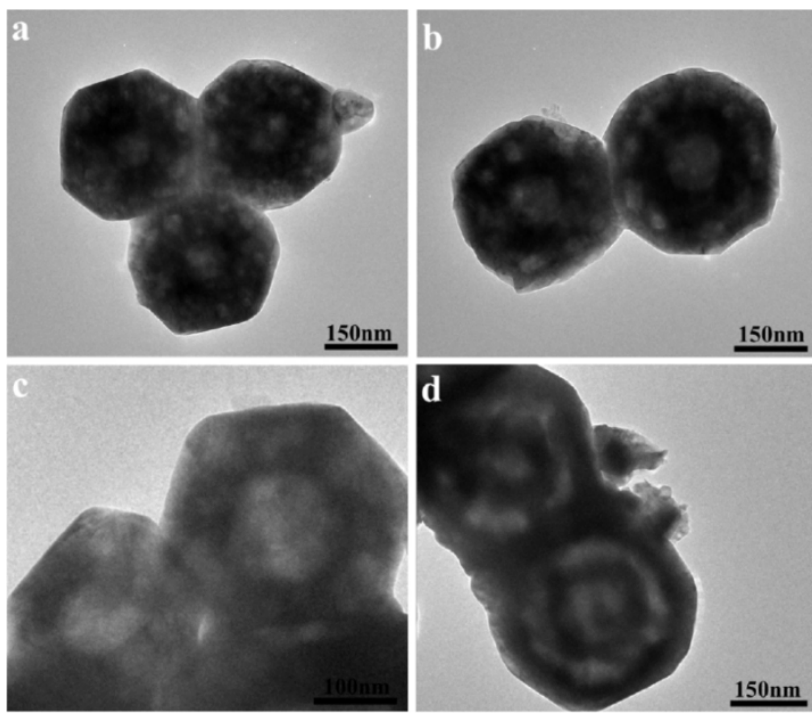

Figure $4 \mid$ TEM images exhibit the formation stages of double-shell $\mathrm{Co}_{3} \mathrm{O}_{4}$ hollow particles prepared by calcination of $\mathrm{CoO}$ particles as the precursor obtained at $260^{\circ} \mathrm{C}$ for varied time durations: (a) $2 \mathrm{~h}$, (b) $4 \mathrm{~h}$, (c) $6 \mathrm{~h}$, and (d) $12 \mathrm{~h}$.

solid particles with average size of about $150 \mathrm{~nm}$, as shown in Figure $2 \mathrm{a}$. Figure $2 \mathrm{~b}$ depicts a typical TEM image of product obtained for $4 \mathrm{~h}$. The mean size of $\mathrm{CoO}$ particles is increased to about $250 \mathrm{~nm}$, suggesting the elongation in size with increasing reaction time. Closer observation reveals that almost all particles possesses hollow interiors at this stage. Extending the reaction time to $12 \mathrm{~h}$, the double-shell structures of the $\mathrm{CoO}$ hollow particles with sizes in the range $300-400 \mathrm{~nm}$ can be observed more clearly (Figure 2c). It is noteworthy that if the reaction time is further extended to $24 \mathrm{~h}$, almost $100 \%$ double-shell $\mathrm{CoO}$ hollow particles with uniform sizes about $500 \mathrm{~nm}$ can be obtained, as shown in Figure 2d. In particular, the outer shell thickness of $\mathrm{CoO}$ hollow particle is increased to about $45 \mathrm{~nm}$, comparable to that of $\mathrm{CoO}$ hollow particles obtained for $12 \mathrm{~h}$.

Double-shelled $\mathrm{Co}_{3} \mathrm{O}_{4}$ hollow particles could be also successfully obtained via calcination method using corresponding $\mathrm{CoO}$ hollow particles obtained at $260^{\circ} \mathrm{C}$ for $8 \mathrm{~h}$ as precursors. Figure $3 \mathrm{a}$ depicts the SEM image of as-prepared $\mathrm{Co}_{3} \mathrm{O}_{4}$ obtained by calcination of corresponding $\mathrm{CoO}$ hollow particles at $600^{\circ} \mathrm{C}$ for $2 \mathrm{~h}$ in air. Compared with $\mathrm{CoO}$ hollow particles, the average size of as-prepared $\mathrm{Co}_{3} \mathrm{O}_{4}$ is estimated to be about $400 \mathrm{~nm}$, which may be related to the possible oxidation of $\mathrm{CoO}$ to $\mathrm{Co}_{3} \mathrm{O}_{4}$. An individual particles with broken shell shown in the inset of Figure 3 a demonstrates the ball-inball structure of the $\mathrm{Co}_{3} \mathrm{O}_{4}$ hollow particles. A typical TEM image of as-prepared $\mathrm{Co}_{3} \mathrm{O}_{4}$ hollow particles is shown in Figure $3 \mathrm{~b}$. Herein, the $\mathrm{Co}_{3} \mathrm{O}_{4}$ hollow particles with double-shell structure can be clearly observed. In the inset, an SAED pattern was well indexed to spinel $\mathrm{Co}_{3} \mathrm{O}_{4}$, revealing a polycrystalline nature of the calcined hollow particles. The double-shell structure is also clearly revealed by TEM observation of an individual $\mathrm{Co}_{3} \mathrm{O}_{4}$ hollow particle, as shown in Figure 3c. The inset displays the corresponding HRTEM image, which provides further insight into the structure of $\mathrm{Co}_{3} \mathrm{O}_{4}$ hollow particle. Lattice spacing is measured to be about $0.23 \mathrm{~nm}$, which is consistent with the interplanar spacings of $\{222\}$ for spinel $\mathrm{Co}_{3} \mathrm{O}_{4}$. Figure $3 \mathrm{~d}$ shows the typical XRD pattern of double-shell $\mathrm{Co}_{3} \mathrm{O}_{4}$ hollow particles. All the reflections in the XRD pattern can be indexed as a face-centered cubic phase of spinel $\mathrm{Co}_{3} \mathrm{O}_{4}$ (JCPDS 431003 ) with lattice constant $\mathrm{a}=0.808 \mathrm{~nm}$ (space group: Fd-3m (No. 227)). No impurity peaks were observed, indicating that cubic $\mathrm{CoO}$ was completely converted into spinel $\mathrm{Co}_{3} \mathrm{O}_{4}$.

The evolution of double-shell structure during the calcination of as-prepared $\mathrm{CoO}$ particles obtained at $260^{\circ} \mathrm{C}$ for varied time durations as the precursor at $600^{\circ} \mathrm{C}$ for $2 \mathrm{~h}$ directly mirrors a possible scenario for the formation of double-shell $\mathrm{Co}_{3} \mathrm{O}_{4}$ hollow particles. Figure 4 summarizes a series of morphological observations of forming double-shell $\mathrm{Co}_{3} \mathrm{O}_{4}$ hollow particles. Figure 4 a shows a typical TEM image of the porous $\mathrm{Co}_{3} \mathrm{O}_{4}$ with hollow interior prepared by calcination of corresponding $\mathrm{CoO}$ particles obtained at $260^{\circ} \mathrm{C}$ for $2 \mathrm{~h}$. With careful observation, the shells of $\mathrm{Co}_{3} \mathrm{O}_{4}$ hollow particles were found to be composed of many pores with a mean diameter of $15 \mathrm{~nm}$. It is noteworthy that if the reaction time of precursors was extended to $4 \mathrm{~h}$, large interior space of $\mathrm{Co}_{3} \mathrm{O}_{4}$ hollow particles can be generated, as shown in Figure $4 \mathrm{~b}$. Typical TEM image shown in Figure $4 \mathrm{c}$ indicates a significant increase of pore sizes in the shells. Furthermore, the interior space is also further improved. This suggests both the expansion in interior space and the addition in pore size with increasing reaction time. More interestingly, $\mathrm{Co}_{3} \mathrm{O}_{4}$ hollow particles with apparent double-shell structure can be clearly identified using $\mathrm{CoO}$ hollow particles as precursors obtained at $260^{\circ} \mathrm{C}$ for 8 and 12 h, as shown in Figure 3 and 4d, respectively.

\section{Discussion}

To investigate the mechanism of double-shell CoO hollow particles, based on the experimental results, the possible scenario for the formation of double-shell $\mathrm{CoO}$ hollow particles is illustrated in Figure 5. Firstly, $\mathrm{Co}(\mathrm{acac})_{2}$ dissolves in organic solvent and then undergoes thermal decomposition to form small particles under solvothermal conditions. Subsequently the fresh small particles is unstable due to the high surface energy and tends to aggregate into larger solid particles driven by the minimization of interfacial energy, which can then convert into hollow particles due to the Ostwald ripening process ${ }^{39}$. Finally, owing to the existence of anisotropic outer surfaces of the hollow particles, hollowing space gradually takes place at a particular region underneath the outer surface and leads to the formation of double-shelled hollow structures ${ }^{40,41}$.

The magnetic properties of double-shell cobalt oxides hollow particles were measured on a superconducting quantum interference device (SQUID). The temperature dependences of the zero-fieldcooled (ZFC) and field-cooled (FC) magnetization of the double-shell CoO hollow particles measured under an applied field of $100 \mathrm{Oe}$ are shown in Figure 6a. It is clear that there is a significant difference between ZFC and FC curves of double-shell $\mathrm{CoO}$ hollow particles at low temperature. Compared with FC curve, the ZFC curve depicts a distinct peak at $4.8 \mathrm{~K}$, suggesting ferromagnetic (FM) behavior below $4.8 \mathrm{~K}$, which may be attributed to superparamagnetic cobalt particles ${ }^{42}$. Figure $6 \mathrm{~b}$ shows the ZFC and FC curves of double-shell $\mathrm{Co}_{3} \mathrm{O}_{4}$ hollow particles measured under an applied field of 100 Oe. The feature indicates the possible presence of antiferromagnetic (AFM) transitions. The AFM transition occurs at $\sim 32 \mathrm{~K}$ (Néel temperature, $T_{\mathrm{N}}$ ), being far lower than that of the bulk $\mathrm{Co}_{3} \mathrm{O}_{4}$ known at about $40 \mathrm{~K}$, which
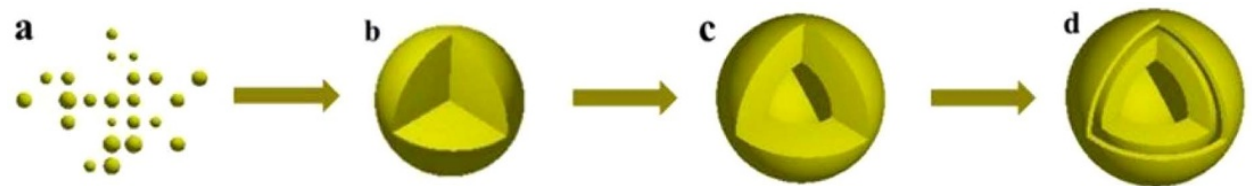

Figure 5 Schematic exhibition of the formation of double-shell CoO hollow particles. 

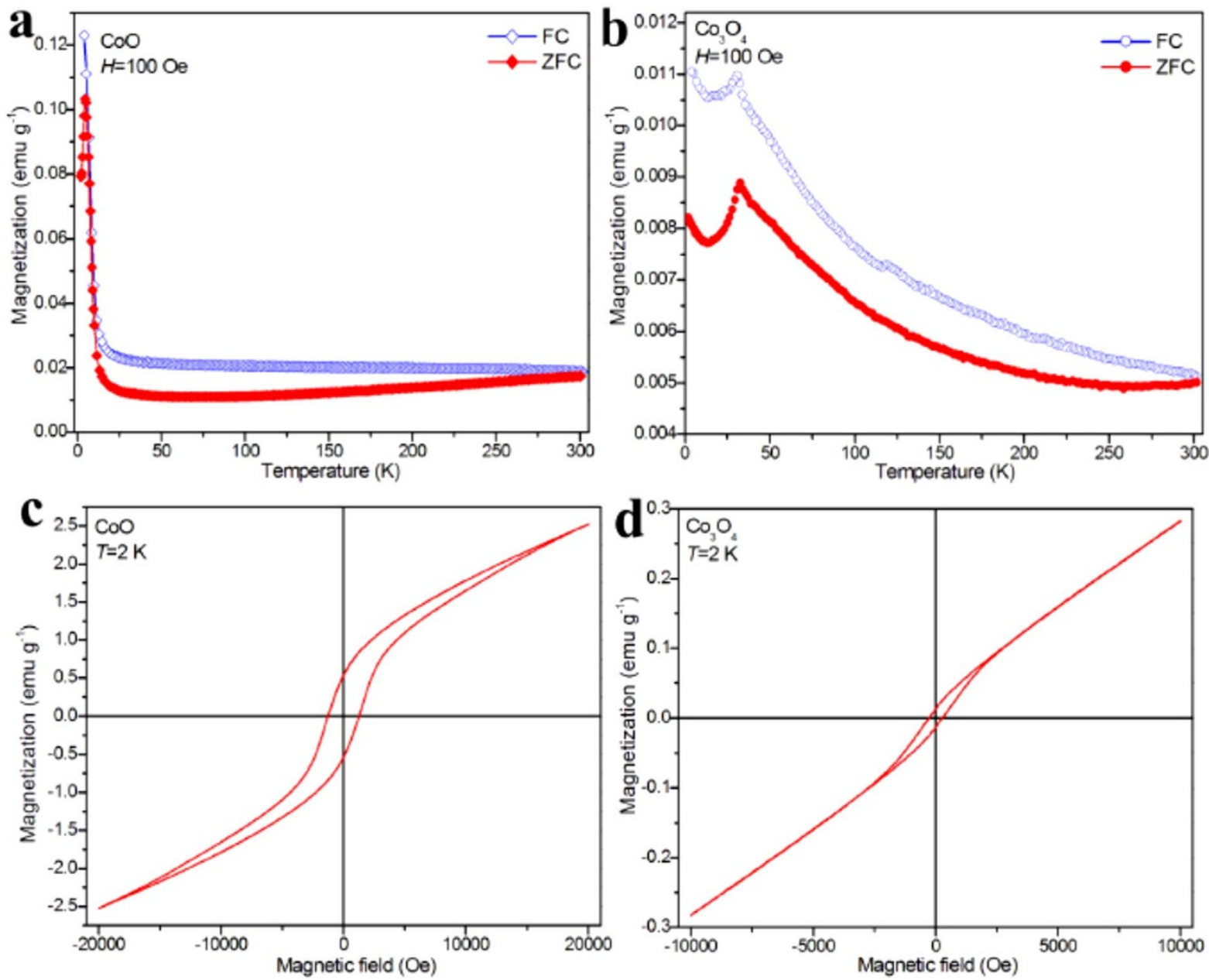

Figure 6 2 ZFC and FC magnetization curves for (a) $\mathrm{CoO}$ and (b) $\mathrm{Co}_{3} \mathrm{O}_{4}$ hollow particles measured under an applied field of 100 Oe. Isothermal magnetization curves for (c) $\mathrm{CoO}$ and (d) $\mathrm{Co}_{3} \mathrm{O}_{4}$ hollow particles at $2 \mathrm{~K}$.

is possibly resulted from the finite size and surface effect of double-shell $\mathrm{Co}_{3} \mathrm{O}_{4}$ hollow particles ${ }^{43,44}$. The hysteresis loops for double-shell $\mathrm{CoO}$ and $\mathrm{Co}_{3} \mathrm{O}_{4}$ hollow particles at $2 \mathrm{~K}$ are shown in Figure $6 \mathrm{c}$ and $\mathrm{d}$, respectively. The coercivity value $H_{\mathrm{c}}$ for the $\mathrm{CoO}$ is about $1298 \mathrm{Oe}$ at $2 \mathrm{~K}$, indicating the presence of ferromagnetic ordering component. For $\mathrm{Co}_{3} \mathrm{O}_{4}$ hollow particles, despite of that the low temperature data show a slight curvature, the magnetization curves are nearly linear at $2 \mathrm{~K}$, also indicative an antiferromagnetic ground state.

\section{Methods}

The synthesis use commercially available reagents: cabalt (II) acetylacetonate $\left(\mathrm{Co}(\mathrm{acac})_{2}\right.$, chemical grade, $98 \%$, a\&k), 1-octadecene (ODE, technical grade, $90 \%$, ACROS), oleic acid (OA, chemical grade, SCRC), and oleylamine (OAm, technical grade, approximate C18-content $80-90 \%$, ACROS) were of chemically pure and used as received.

Preparation of double-shell $\mathrm{CoO}$ hollow particles. Typical synthetic procedures are summarized as follows: $0.2571 \mathrm{~g} \mathrm{Co}(\mathrm{acac})_{2}(1 \mathrm{mmol})$ was dissolved into $20 \mathrm{~mL} \mathrm{ODE}$ with $\mathrm{OA}$ and $\mathrm{OAm}$ (in molar ratios of $4: 10$ ) to form colloid mixture under vigorous stirring for $10 \mathrm{~min}$ at room temperature. Then the mixture was sealed in a Teflonlined and maintained at $260^{\circ} \mathrm{C}$ for $1-24 \mathrm{~h}$. The autoclave was cooled to room temperature. The brown products were washed for several times with absolute ethanol and hexane. Finally, the products were dried in vacuum at $60^{\circ} \mathrm{C}$ for $6 \mathrm{~h}$.

Preparation of double-shell $\mathrm{Co}_{3} \mathrm{O}_{4}$ hollow particles. The double-shell $\mathrm{Co}_{3} \mathrm{O}_{4}$ hollow particles could be prepared by the thermal decomposition of as-prepared $\mathrm{CoO}$ hollow particles obtained at $260^{\circ} \mathrm{C}$ for $2-12 \mathrm{~h}$ as precursors calcinated at $600^{\circ} \mathrm{C}$ for $2 \mathrm{~h}$ in air.

Characterization. The structure and phase composition of the products were characterized on a X-ray diffractometer (XRD, D/max2550 VB+) with $\mathrm{Cu}$ $\mathrm{K} \alpha$ radiation $(\lambda=1.5418 \AA)$. The morphologies and sizes of the products were characterized by a field-emission scanning electron microscopy (FE-SEM, Sirion 200) and transmission electron microscope (TEM, Tecnai G2 F20). High-resolution TEM (HRTEM) images and SAED patterns were obtained from the TEM. Magnetic measurements were conducted using a Quantum Design MPMS XP-5 superconducting quantum interference device (SQUID).

1. Zhao, Y. \& Jiang, L. Hollow micro/nanomaterials with multilevel interior structures. Adv. Mater. 21, 3621-3638 (2009).

2. Xu, S. et al. $\alpha-\mathrm{Fe}_{2} \mathrm{O}_{3}$ Multi-shelled hollow microspheres for lithium ion battery anodes with superior capacity and charge retention. Energy Environ. Sci. 7, 632-637 (2014)

3. Wang, X. et al. Synthesis and lithium storage properties of $\mathrm{Co}_{3} \mathrm{O}_{4}$ nanosheetassembled multishelled hollow spheres. Adv. Funct. Mater. 20, 1680-1686 (2010).

4. Wu, H. B., Pan, A. Q., Hng, H. H., Lou, X. \& Lou, W. Template-assisted formation of rattle-type $\mathrm{V}_{2} \mathrm{O}_{5}$ hollow microspheres with enhanced lithium storage properties. Adv. Funct. Mater. 23, 5669-5674 (2013).

5. Zhang, H. et al. One-pot synthesis and hierarchical assembly of hollow $\mathrm{Cu}_{2} \mathrm{O}$ microspheres with nanocrystals-composed porous multishell and their gassensing properties. Adv. Funct. Mater. 17, 2766-2711 (2007).

6. Lai, X. Y. et al. General synthesis and gas-sensing properties of multiple-shell metal oxide hollow microspheres. Angew. Chem. Int. Ed. 50, 2738-2741 (2011).

7. Zeng, Y. et al. Multi-shelled titania hollow spheres fabricated by a hard template strategy: enhanced photocatalytic activity. Chem. Commun. 46, 4312-4314 (2010).

8. Cao, L., Chen, D. H. \& Caruso, R. A. Surface-metastable phase-initiated seeding and ostwald ripening: a facile fluorine-free process towards spherical fluffy core/ shell, yolk/shell, and hollow anatase nanostructures. Angew. Chem. Int. Ed. 52, 10986-10991 (2013).

9. Dong, Z. H. et al. Quintuple-shelled $\mathrm{SnO}_{2}$ hollow microspheres with superior light scattering for high-performance dye-sensitized solar cells. Adv. Mater. 26, 905-909 (2014).

10. Dong, Z. H. et al. Accurate control of multishelled $\mathrm{ZnO}$ hollow microspheres for dye-sensitized solar cells with high efficiency. Adv. Mater. 24, 1046-1049 (2012). 
11. Tan, L. F. et al. Uniform double-shelled silica hollow spheres: acid/base selectiveetching synthesis and their drug delivery application. RSC Adv. 3, 5649-5655 (2013).

12. Liu, J., Qiao, S. Z., Hartono, S. B. \& Lu, G. Q. (Max) Monodisperse yolk-shell nanoparticles with a hierarchical porous structure for delivery vehicles and nanoreactors. Angew. Chem. Int. Ed. 49, 4981-4985 (2010).

13. Lou, X. W., Yuan, C. L. \& Archer, L. A. Shell-by-shell synthesis of tin oxide hollow colloids with nanoarchitectured walls: Cavity size tuning and functionalization. Small 3, 261-265 (2007).

14. Xiong, S. L. \& Zeng, H. C. Serial ionic exchange for the synthesis of multishelled copper sulfide hollow spheres. Angew. Chem. Int. Ed. 51, 949-952 (2012).

15. Wang, D. P. \& Zeng, H. C. Creation of interior space, architecture of shell structure, and encapsulation of functional materials for mesoporous $\mathrm{SiO}_{2}$ spheres. Chem. Mater. 23, 4886-4899 (2011).

16. Zeng, H. C. Synthetic architecture of interior space for inorganic nanostructures. J. Mater. Chem. 16, 649-662 (2006).

17. Cao, L., Chen, D. H. \& Caruso, R. A. Surface-metastable phase-initiated seeding and ostwald ripening: a facile fluorine-free process towards spherical fluffy core/ shell, yolk/shell, and hollow anatase nanostructures. Angew. Chem. Int. Ed. 52, 10986-10991 (2013).

18. Zeng, H. C. Ostwald Ripening: A synthetic approach for hollow nanomaterials. Curr. Nanosci. 3, 177-181 (2007).

19. Xie, L., Zheng, J., Liu, Y., Li, Y. \& Li, X. G. Synthesis of $\mathrm{Li}_{2} \mathrm{NH}$ hollow nanospheres with superior hydrogen storage kinetics by plasma metal reaction. Chem. Mater. 20, 282-286 (2008).

20. An, K. et al. Synthesis of uniform hollow oxide nanoparticles through nanoscale acid etching. Nano Lett. 8, 4252-4258 (2008).

21. Li, G. L. et al. Alternating silica/Polymer multilayer hybrid microspheres templates for double-shelled polymer and inorganic hollow microstructures. Chem. Mater. 22, 1309-1317 (2010).

22. Zhang, L. \& Wang, H. Interior structural tailoring of $\mathrm{Cu}_{2} \mathrm{O}$ shell-in-shell nanostructures through multistep ostwald ripening. J. Phys. Chem. C 115 18479-18485 (2011).

23. Wang, D. P. \& Zeng, H. C. Creation of interior space, architecture of shell structure, and encapsulation of functional materials for mesoporous $\mathrm{SiO}_{2}$ spheres. Chem. Mater. 23, 4886-4899 (2011).

24. Yec, C. C. \& Zeng, H. C. Synthetic architecture of multiple core-shell and yolkshell structures of $\left(\mathrm{Cu}_{2} \mathrm{O} @\right) \mathrm{nCu}_{2} \mathrm{O}(\mathrm{n}=1-4)$ with centricity and eccentricity. Chem. Mater. 24, 1917-1929 (2012).

25. Shi, R. R. et al. Shape-controlled synthesis and characterization of cobalt oxides hollow spheres and octahedra. Dalton Trans. 41, 5981-5987 (2012).

26. Liu, X. H., Ma, R. Z., Bando, Y. \& Sasaki, T. Layered cobalt hydroxide nanocones: microwave-assisted synthesis, exfoliation, and structural modification. Angew. Chem. Int. Ed. 49, 8253-8256 (2010).

27. Liu, X. H., Ma, R. Z., Bando, Y. \& Sasaki, T. High-yield preparation, versatile structural modification, and properties of layered cobalt hydroxide nanocones. Adv. Funct. Mater. 24, 4292-4302 (2014).

28. Li, T. et al. Topotactic conversion route to mesoporous quasi-single-crystalline $\mathrm{Co}_{3} \mathrm{O}_{4}$ nanobelts with optimizable electrochemical performance. Adv. Funct. Mater. 22, 617-623 (2010)

29. Liu, X. H. et al. Cobalt hydroxide nanosheets and their thermal decomposition to cobalt oxide nanorings. Chem.-Asian J. 3, 732-738 (2008).

30. Liu, X. H., Qiu, G. Z. \& Li, X. G. Shape-controlled synthesis and properties of uniform spinel cobalt oxide nanocubes. Nanotech 16, 3035-3040 (2005).

31. Xu, R. \& Zeng, H. C. Self-generation of tiered surfactant superstructures for onepot synthesis of $\mathrm{Co}_{3} \mathrm{O}_{4}$ nanocubes and their close- and non-close-packed organizations. Langmuir 20, 9780-9790 (2004).
32. Xu, R. \& Zeng, H. C. Mechanistic investigation on salt-mediated formation of freestanding $\mathrm{Co}_{3} \mathrm{O}_{4}$ nanocubes at $95^{\circ}$ C. J. Phys. Chem. B 107, 926-930 (2003).

33. Feng, J. \& Zeng, H. C. Size-controlled growth of $\mathrm{Co}_{3} \mathrm{O}_{4}$ nanocubes. Chem. Mater. 15, 2829-2835 (2003)

34. Keng, P. Y. et al. Colloidal polymerization of polymer-coated ferromagnetic nanoparticles into cobalt oxide nanowires. ACS Nano. 3, 3143-3157 (2009)

35. Zhuo, L. H., Ge, J. C. \& Cao, L. H. Solvothermal synthesis of $\mathrm{CoO}, \mathrm{Co}_{3} \mathrm{O}_{4}, \mathrm{Ni}(\mathrm{OH})_{2}$ and $\mathrm{Mg}(\mathrm{OH})_{2}$ nanotubes. Cryst. Growth Des. 9, 1-6 (2009).

36. Wang, X. et al. Synthesis and lithium storage properties of $\mathrm{Co}_{3} \mathrm{O}_{4}$ nanosheetassembled multishelled hollow spheres. Adv. Funct. Mater. 20, 1680-1686 (2010)

37. Wang, J. Y. et al. Accurate control of multishelled $\mathrm{Co}_{3} \mathrm{O}_{4}$ hollow microspheres as high-performance anode materials in lithium-ion batteries. Angew. Chem. Int. Ed. 52, 6417-6420 (2013)

38. Lai, X. Y. et al. General synthesis and gas-sensing properties of multiple-shell metal oxide hollow microspheres. Angew. Chem. Int. Ed. 50, 2738-2741 (2011)

39. Li, J. \& Zeng, H. C. Hollowing Sn-doped $\mathrm{TiO}_{2}$ nanospheres via ostwald ripening. J. Am. Chem. Soc. 129, 15839-15847 (2007).

40. Xie, Q. S. et al. Template-free synthesis of amorphous double-shelled zinc-cobalt citrate hollow microspheres and their transformation to crystalline $\mathrm{ZnCo}_{2} \mathrm{O}_{4}$ microspheres. ACS Appl. Mater. Inter. 5, 5508-5517 (2013).

41. Liu, J., Xia, H., Xue, D. F. \& Lu, L. Double-shelled nanocapsules of $\mathrm{V}_{2} \mathrm{O}_{5}$-based composites as high-performance anode and cathode materials for Li Ion batteries. J. Am. Chem. Soc. 131, 12086-12087 (2009).

42. Kundu, S., Nelson, A. J., McCall, S. K., Buuren, T. V. \& Liang, H. Shape-influenced magnetic properties of CoO nanoparticles. J. Nanopart Res. 15, 1587-1600 (2013)

43. Roth, W. L. The magnetic structure of $\mathrm{Co}_{3} \mathrm{O}_{4}$. J. Phys. Chem. Solids 25, 1-10 (1964).

44. He, L., Chen, C. P., Wang, N., Zhou, W. \& Guo, L. Finite size effect on Neel temperature with $\mathrm{Co}_{3} \mathrm{O}_{4}$ nanoparticles. J. Appl. Phys. 102, 103911-103923 (2007).

\section{Acknowledgments}

Financial support of this work by National Natural Science Foundation of China (51372279), Hunan Provincial Natural Science Foundation of China (13JJ1005) and Shenghua Scholar Program of Central South University is gratefully acknowledged.

\section{Author contributions}

D.Z., J.Z., X.L. and G.Q. conceived and designed the experiments, and X.L. and G.Q. supervised the research; N.Z., T.L. and L.C. helped to synthesize the hollow spheres; R.M and H.Z. assisted in the SQUID studies; D.Z. performed the synthesis and characterization, interpreted the data and wrote the paper with help from X.L. and G.Q.

\section{Additional information}

Competing financial interests: The authors declare no competing financial interests. How to cite this article: Zhang, D. et al. Controllable fabrication and magnetic properties of double-shell cobalt oxides hollow particles. Sci. Rep. 5, 8737; DOI:10.1038/srep08737 (2015).

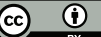

This work is licensed under a Creative Commons Attribution 4.0 International License. The images or other third party material in this article are included in the article's Creative Commons license, unless indicated otherwise in the credit line; if the material is not included under the Creative Commons license, users will need to obtain permission from the license holder in order to reproduce the material. To view a copy of this license, visit http://creativecommons.org/licenses/by/4.0/ 